\title{
Hubungan Motivasi Pasien dengan Kemampuan Mengontrol Resiko Kekambuhan Penyakit Jantung Koroner di RSUD Raden Mattaher Jambi
}

\author{
Bettywati E Tumanggor \\ Jurusan Keperawatan Politeknik Kesehatan Kemenkes Jambi \\ Correspondence email: bettywati484@gmail.com
}

\begin{abstract}
Abstrak. Penyakit Jantung Koroner (PJK) merupakan penyakit tidak menular sebagai penyebab kematian nomor satu di dunia. PJK di Indonesia menjadi pravelensi tertinggi untuk penyakit kardiovaskuler. Diperlukan upaya pencegahan baik primer, sekunder maupun tertier untuk pengendalian faktor risiko PJK. Tujuan penelitian ini untuk mengetahui hubungan motivasi pasien dengan kemampuan mengontrol resiko kekambuhan penyakit jantung koroner di RSUD Raden Mattaher Jambi tahun 2018. Desain yang digunakan dalam penelitian ini adalah penelitian kuantitatif dengan pendekatan cross sectional mengambil 84 orang sebagai sampel secara purposive sampling. Data Penelitian dianalisis secara univariat dan bivariat menggunakan uji chi square dengan derajat kemaknaan $\mathrm{p}<0,05$ Hasil penelitian menunjukkan bahwa ada hubungan yang bermakna antara motivasi pasien dengan kemampuan mengontrol resiko kekambuhan PJK. Diperlukan adanya pemberian pendidikan kesehatan terkait upaya pencegahan PJK untuk lebih meningkatkan pemahaman serta meningkatkan motivasi positif pasien. Seperti dengan menyediakan waktu khusus untuk memberikan pendidikan kesehatan pada pasien dan keluarga, membagikan leaflet, atau menayangkan video khusus mengenai pencegahan PJK yang dapat dilihat pasien sembari menunggu antrean di poliklinik jantung.
\end{abstract}

Kata Kunci: motivasi; kemampuan; faktor risiko PJK

\begin{abstract}
Coronary Heart Disease (CHD) is a non-contagious disease as the number one cause of death in the world. CHD in Indonesia becomes the highest pravency for cardiovascular disease. Primary, secondary and tertiary prevention is needed to control CHD risk factors. The purpose of this study to determine the correlation between motivation of patients with the ability to control the Risk of Coronary Heart Disease Recurrence at hospitals Raden Mattaher Jambi 2018. The design used in this study is quantitative research with cross sectional approach to take 84 people as a sample by purposive sampling. Research data were analyzed univariat and bivariate using chi square test with significance level $p<0,05$. The result showed that there was a significant correlation between motivation of patient with ability to control the risk of CHD Recurrence. Required the provision of health education related to the prevention of CHD to further improve understanding and improve the positive motivation of patients. Such as providing a special time to provide health education to patients and families, distributing leaflets, or showing special videos of CHD prevention that patients can see while waiting for a line at the heart polyclinic.
\end{abstract}

Keywords: motivation; ability; CHD risk factors

\section{PENDAHULUAN}

Penyakit Jantung Koroner (PJK) merupakan Penyakit Tidak Menular (PTM) sebagai penyebab kematian nomor satu didunia. Data WorldHealthOrganization (WHO) tahun 2015 melaporkan 17,7 juta orang di dunia meninggal akibat penyakit kardiovaskular. Presentase data tersebut mewakili $31 \%$ dari jumlah kematian diseluruh dunia. Total kematian tersebut, diperkirakan 7,4 juta diantarnya disebabkan oleh penyakit jantung koroner (WHO, 2015). Menurut institusi jantung, paru-paru dan darah nasional Amerika Serikat (National Heart, Lung, and Blood Institute) yang dikutip dalam Notoatmodjo, (2014), menyatakan bahwa PJK merupakan penyebab kematian nomor satu. Penelitian baik pada pria maupun wanita di Amerika Serikat, menunjukkan jumlah kematian yang tinggi akibat PJK. Total data jumlah kematian yang dilaporkan akibat penyakit ini mencapai lebih dari 500.000 jiwa setiap tahunnya.

Data Riset Kesehatan Dasar (Riskesdas) tahun 2013 menunjukkan,bahwa prevalensi tertinggi untuk penyakit kardiovaskuler di Indonesia adalah PJK.
Prevalensi PJK berdasarkan diagnosis dokter/gejala yakni sebesar 1,5\% atau diperkirakan sekitar 2.650.340 orang. Prevalensi PJK di Indonesia tahun 2013 berdasarkan diagnosis dokter, sebesar $0,5 \%$ atau diperkirakan sekitar 883.447 orang (Riskesdas, 2013). Prevalensi PJK pada setiap propinsi di Indonesia memberi kontribusi paling kecil $0,2 \%$ dari jumlah total prevalensi PJK.

Prevalensi PJK di Propinsi Jambi tahun 2013 berdasarkan diagnosis dokter, sebesar $0,2 \%$ atau diperkirakan sekitar 4.625 orang. Sedangkan prevalensi berdasarkan diagnosis dokter/gejala sebesar $0,5 \%$ atau diperkirakan sekitar 11.563 orang (Info Datin, Kemenkes, 2014).

Menurut laporan medical record di RSUD Raden Mattaher Jambi, didapatkan hasil laporan kasus PJK pada tahun 2015 dengan jumlah total kunjungan kasus PJK yaitu 1.990 kasus, dengan jumlah kasus baru sejumlah $108(5,42 \%)$ dan kasus lama $1.882(94,57$ Data kasus PJK pada tahun 2017 dengan jumlah total kunjungan kasus PJK yaitu 4.358 kasus, dengan jumlah kasus baru $621(14,24 \%)$ dan kasus lama 3.737 
$(85,75 \%)$. Dengan demikian diperoleh data insiden PJK terus meningkat dari tahun 2016 sebanyak 213 (3,95\%) kasus baru, kemudian meningkat tahun 2017 sebesar 300(4,87\%) kasus baru (Medical RecordRSUD Raden Mattaher Jambi tahun 2017). PJK atau dikenal dengan Coronary Artery Disease (CAD) adalah suatu kondisi yang disebabkan suplai darah dan oksigen ke miokardium yang tidak adekuat, sehingga terjadi ketidakseimbangan kebutuhan dan suplai darah (Tanto, et.al 2014). Lebih lanjut, PJK merupakan penyakit yang menyangkut pembuluh darah koroner, yang dalam mengenal dan menanganinya membutuhkan perhatian serta pengenalan dari faktor resiko yang ada pada penderita (Naga, 2012).

Terdapat beberapa faktor resiko PJK yaitu faktor resiko yang dapat dimodifikasi (modifiable) dan faktor resiko yang tidak dapat dimodifikasi (nonmodifiable). Faktor resiko modifiable dapat dikontrol dengan mengubah gaya hidup atau kebiasaan pribadi, sedangkan faktor nonmodifiable merupakan konsekuensi genetik yang tidak dapat dikontrol. Semakin banyak faktor resiko yang dimiliki seseorang, semakin besar kemungkinan terjadinya penyakit arteri koroner. (Smeltzer \& Bare, 2002).

Faktor resiko yang dapat dimodifikasi antara lain diet (pola makan), tinggi lemak atau kolestrol, tekanan darah tinggi, diabetes mellitus, merokok, obesitas, stress dan kurang gerak. Sedangkan faktor resiko yang tidak dapat dimodifikasi antara lain usia (biasanya > 40 tahun), jenis kelamin serta riwayat keluarga (Asikin et.al, 2016).

Sementara itu, pencegahan PJK bisa bersifat primer, sekunder dan tertier Pencegahan primer meliputi segala usaha yang dilakukan sebelum timbulnya gejala proses penyakit. Sedangkan pencegahan sekunder meliputi segala usaha yang dilakukan untuk mengurangi perkembangan atau mencegah kekambuhan proses penyakit (Smelttzer \& Bare, 2002). Pencegahan tertier yaitu upaya untuk mencegah terjadinya komplikasi yang lebih berat atau kematian serta usaha rehabilitasi (Nasution, NH, 2010).

Penelitian yang dilakukan oleh Indrawati (2012) tentang hubungan antara pengetahuan, sikap, persepsi motivasi, dukungan keluarga dan sumber informasi pasien penyakit jantug koroner dengan tindakan pencegahan sekunder di RSPAD Gatot Soebroto Jakarta, didapatkan bahwa sebagian besar memilki pengetahuan yang baik $(55,9 \%)$, sebagian memilki sikap yang positif (67,6\%), sebagian lagi memiliki persepsi diri yang positif $(64,7 \%)$, hampir seluruhnya memiliki motivasi diri yang baik $(88,2 \%)$, sebagian didukung oleh keluarga $(51,5 \%)$, sebagian besar pernah mendapatkan informasi sebelumnya tentang PJK (73,5\%) dan sebagian lagi memiliki kemampuan yang baik dalam melakukan pencegahan sekunder faktor resiko PJK (55,9\%). Kejadian kekambuhan yang terjadi sering kali disebabkan ketidakpatuhan dan ketidakmampuan pasien untuk mengontrol resiko terjadinya kekambuhan PJK. Salah satu upaya yang dapat dilakukan untuk menekan prevalensi PJK yaitu dengan meningkatkan kesadaran pasien mengidentifikasi faktor resiko dan melakukan manajemen preventif (Smelttzer \& Bare, 2002).

Motivasi yang dirumuskan oleh Terry G dalam Bastabel (2002) adalah keinginan yang terdapat pada diri seseorang individu yang mendorongnya untuk melakukan perbuatan-perbuatan (perilaku). Sedangkan stooner dalam Bastabel (2002), mendefinisikan bahwa motivasi adalah sesuatu hal yang menyebabkan dan yang mendukung tindakan atau perilaku seseorang. Secara individual motivasi seseorang sangatlah personal, satu dengan yang lainnya berbeda. Berdasarkan teori Lawrence Green dalam Notoatmodjo (2007) yang menyebutkan bahwa perilaku seseorang ditentukan salah satunya oleh motivasi. Meskipun demikian, tujuan mendasar dari motivasi adalah untuk mendapatkan sesuatu atau terhindar dari sesuatu mendapatkan sesuatu cenderung konteksnya positif dan menghindari sesuatu

cenderung berkonteks negatif seperti hukuman (Donsu, (2017).

Tujuan Penelitian ini Untuk menganalisis hubungan motivasi pasien dengan kemampuan mengontrol resiko kekambuhan penyakit jantung coroner

\section{METODE}

Penelitian ini dilakukan dengan pendekatan kuantitatif desain cross sectional. ). Sampel yang digunakan pada peneltian ini adalah pasien yang menderita penyakit jantung koroner (PJK) di Poli jantung Rumah Sakit Umum Raden Mattaher.Tehnik pengambilan sampel yang berjumlah 84 responden menggunakan probability sampling. Instrument penelitian yang digunakan adalah lembar kuisioner dari Heart Disease Fact Questionnaire versi modifikasi oleh Dalusung (2010) untuk motivasi pasien dengan kamampuan mengontrol resiko kekambuhan penyakit jantung koroner (PJK).

\section{HASIL DAN PEMBAHASAN}

Hasil pengambilan data dianalisis dengan univariat dan bivariat. Berdasarkan hasil penelitian diketahui distribusi frekuensi motivasi responden di Poliklinik Jantung RSUD Raden Mattaher dapat dilihat pada tabel berikut:

Tabel 1. Distribusi Frekuensi Responden Berdasarkan Motivasi di Poliklinik Jantung RSUD Raden Mattaher Jambi Tahun 2018 (n: 84)

\begin{tabular}{ccc}
\hline Motivasi Pasien & Frekuensi & Presentase \\
\hline Baik & 75 & $89,3 \%$ \\
Tidak Baik & 9 & $10,7 \%$ \\
Jumlah & 84 & $100 \%$ \\
\hline
\end{tabular}


Berdasarkan tabel 1 didapatkan bahwa sebagian besar motivasi responden baik dalam mengontrol resiko kekambuhan PJK sebanyak 75 responden $(89,3 \%)$.

Tabel 2. Distribusi Frekuensi Responden Berdasarkan Kemampuan dalam Mengontrol Resiko Kekambuhan Penyakit Jantung Koroner di Poliklinik Jantung RSUD Raden Mattaher Jambi Tahun 2018 (n: 84)

\begin{tabular}{ccc}
\hline Kemampuan Pasien & Frekuensi & Presentase \\
\hline Mampu & 71 & $84,5 \%$ \\
Tidak Mampu & 13 & $15,5 \%$ \\
Jumlah & 84 & $100 \%$ \\
\hline
\end{tabular}

Berdasarkan tabel 2 didapatkan bahwa sebagian besar responden memiliki kemampuan dalam mengontrol resiko kekambuhan penyakit jantung koroner sebanyak 71 responden $(84,5 \%)$.

Hubungan Motivasi Pasien dengan Kemampuan Mengontrol Resiko Kekambuhan Penyakit Jantung Koroner di RSUD Raden Mattaher Jambi

Tabel 3. Analisis Hubungan Motivasi Pasien dengan Kemampuan Mengontrol Resiko Kekambuhan Penyakit Jantung Koroner (n: 84)

\begin{tabular}{|c|c|c|c|c|c|c|c|}
\hline \multirow[t]{3}{*}{$\begin{array}{l}\text { Motivasi } \\
\text { Pasien }\end{array}$} & \multicolumn{4}{|c|}{$\begin{array}{l}\text { Kemampuan Mengontrol } \\
\text { Resiko Kekambuhan PJK }\end{array}$} & \multicolumn{2}{|c|}{ Total } & \multirow[t]{2}{*}{$\begin{array}{c}p- \\
\text { value }\end{array}$} \\
\hline & \multicolumn{2}{|c|}{ Mampu } & \multicolumn{2}{|c|}{ Tidak Mampu } & & & \\
\hline & $\mathrm{F}$ & $\%$ & $\mathrm{~F}$ & $\%$ & $\mathrm{~F}$ & $\%$ & \\
\hline Baik & 67 & 89,3 & 8 & 10,7 & 75 & 100 & 0,004 \\
\hline Tidak Baik & 4 & 44,4 & 5 & 55,6 & 9 & 100 & \\
\hline Total & 71 & 84,5 & 13 & 15,5 & 84 & 100 & \\
\hline
\end{tabular}

Berdasarkan tabel 3 diketahui bahwa 75 responden yang memiliki motivasi baik sebanyak $89,3 \%$ memiliki kemampuan dalam mengontrol resiko kekambuhan penyakit jantung koroner. Sedangkan 9 responden yang memiliki motivasi tidak baik sebanyak $55,6 \%$ responden tidak mampu mengontrol resiko kekambuhan penyakit jantung coroner.

Hasil uji chi-square di peroleh nilai $p$-value $=$ $0,004<0,05$, sehingga dapat disimpulkan dari hasil uji statistik ini bahwa ada hubungan yang bermakna antara motivasi pasien dengan kemampuan mengontrol resiko kekambuhan penyakit jantung koroner. Hasil penelitian ini menunjukan bahwa sebagian besar motivasi responden baik yaitu 89,3\%. Motivasi seperti dirumuskan oleh Terry G dalam Bastabel (2002) merupakan keinginan yang terdapat pada diri seorang individu yang mendorongnya untuk melakukan perbuatan-perbuatan (perilaku). Semakin baik motivasi seseorang maka akan semakin kuat dorongan untuk melakukan suatu perilaku dalam hal ini motivasi untuk mengontrol resiko kekambuhan PJK. Motivasi yang baik ditunjukkan responden untuk menjaga berat badannya agar tidak obesitas yakni sebesar 50\%, responden juga memilki motivasi yang baik untuk menyeimbangkan antara aktivitas dan kebutuhan istirahat sebanyak $63.1 \%$. Responden memiliki motivasi yang baik untuk berhenti merokok dan sebisa mungkin terhindar dari asap rokok yakni sebesar $77.4 \%$ responden.

Hasil penelitian ini menunjukan kemampuan, sebagian besar responden mampu dalam mengontrol resiko kekambuhan PJK yaitu sebanyak 84,5\%.

Banyak pasien penyakit jantung koroner yang tidak menyadari dirinya mengalami gejala penyakit jantung dan banyak pasien yang menganggap bahwa pola hidupnya selama ini tidak ada masalah namun tetap saja terkena penyakit jantung koroner. Oleh karena itu sangat penting untuk mempersiapkan kemampuan pasien dalam melakukan upaya pencegahan dan pengontrolan resiko agar penyakit jantung koroner tidak terulang kembali.Semakin baik kemampuan yang dimiliki pasien dalam mengontrol resiko kekambuhan PJK, maka kemungkinan resiko kekambuhan PJK pun dapat diminimalisir.

Hasil uji statistik didapatkan bahwa ada hubungan yang bermakna antara motivasi pasien dengan kemampuan mengontrol resiko kekambuhan penyakit jantung koroner. Penelitian ini menunjukkan bahwa dari 75 responden yang memiliki motivasi baik sebanyak 89,3\% memiliki kemampuan dalam mengontrol resiko kekambuhan penyakit jantung koroner. Sedangkan 9 responden yang memiliki motivasi tidak baik, sebanyak $55,6 \%$ responden tidak mampu mengontrol resiko kekambuhan penyakit jantung koroner.

Hal ini menunjukkan bahwa lebih banyak responden dengan motivasi baik yang mampu untuk melakukan kontrol resiko kekambuhan PJK dibandingkan dengan responden yang memiliki motivasi tidak baik. Seorang pasien jantung yang memiliki motivasi yang baik untuk mencegah kekambuhan berulang, tentunya juga memiliki kemampuan untuk konsisten dalam pencegahan. teori motivasi Maslow dalam Notoatmodjo (2007)menyebutkan bahwa motivasi merupakan motor penggerak dari setiap kegiatan yang dilakukan. Sehingga makin besar motivasi maka akan semakin besar pula kemungkinan seseorang untuk berperilaku atau bertindak.

\section{SIMPULAN}

Motivasi responden dalam mengontrol resiko kekambuhan penyakit jantung koroner menunjukan bahwa sebagian besar motivasi responden baik yaitu $89,3 \%$, Kemampuan responden dalam mengontrol resiko kekambuhan penyakit jantung koroner menunjukkan bahwa sebagian besar responden mampu dalam mengontrol resiko kekambuhan PJK yaitu sebanyak $84,5 \%$ dan ada hubungan yang bermakna antara motivasi pasien dengan kemampuan mengontrol resiko kekambuhan penyakit jantung koroner di RSUD Raden Mattaher Jambi Tahun 2018. Ruangan poliklinik jantung, sebagai tempat yang paling rutin dikunjungi pasien, diperlukan adanya pemberian pendidikan kesehatan terkait upaya pencegahan PJK untuk lebih 
Bettywati E Tumanggor, Hubungan Motivasi Pasien dengan Kemampuan Mengontrol Resiko Kekambuhan Penyakit Jantung Koroner di RSUD Raden Mattaher Jambi

meningkatkan pemahaman serta meningkatkan motivasi positif pasien mengenai faktor-faktor yang dapat menyebabkan kekambuhan PJK.

\section{DAFTAR PUSTAKA}

Agustin,Ratna.(2017).Upaya Pencegahan Kekambuhan Melalui Discharge Planning Pada Pasien Penyakit Jantung Koroner https://www.researchgate.net/publication/3229286 07_Upaya_Pencegahan_Kekambuhan_Melalui_Di scharge_Planning_Pada_Pasien_Penyakit_Jantung Koroner/fulltext diakses tanggal 8 Juni 2018

Ambarwati, Ayu Nisma.(2017).Analisis Faktor-Faktor Yang Mempengaruhi Upaya Pencegahan Penyakit Jantung Koroner (PJK) di Desa Pandes Tasikmadu Karangnyar. https://ejurnal.akperpantikosala.ac.id/index.php/jik /article/download/114/

Asikin et.al. 2016. Keperawatan Medikal Bedah Sistem Kardiovaskular. Jakarta: Erlangga

Donsu, Janie. 2017. Psikologi Keperawatan. Yogyakarta: Pustaka Baru Press

Gray, et.al. (2005). Lectures Note Kardiologi Edisi keempat. Jakarta: Penerbit Erlangga

Heart Disease Fact Questionnaire versi modifikasi oleh Dalusung. (2010) diakses tanggal 18 Oktober 2017

Info Datin, Kemenkes, Pusat Data dan Informasi 2014 diakses tanggal 26 oktober 2017

Laporan Hasil Kesehatan Riset Kesehatan (RISKESDAS) Indonesia tahun 2013 diskses tanggal 26 Oktober 2017

Lina Indrawati.(2012). Analisis Faktor Yang Berhubungan Dengan KemampuanPasien Pjk Melakukan Pencegahan Sekunder Faktor Risiko Di Rspad GatotSoebroto Jakarta.

http://ejournal.jurwidyakop3.com/index.php/jurnalilmiah /article/download/192/170 diakses tanggal 18 Oktober 2017

Medical Record RSUD Raden Mattaher Jambi tahun 2015, 2016, 2017

Naga, S Sholeh.2012.Buku Panduan Lengkap Ilmu Penyakit Dalam. Yogyakarta: Diva Press

.(2010). Ilmu Perilaku Kesehatan. Jakarta. PT Rineka Cipta`

Nursallam.2013. Metodologi Penelitian Ilmu Keperawatan. Jakarta: Salemba Medika

Persatuan Dokter Spesialis Kardiovaskular Indonesia. (2014). Pedoman Tatalaksana Sindrom Koroner Akut. Jakarta:Centra Communication

Rahmawati Shoufiah. (2016). Hubungan Faktor Resiko Dan Karakteristik Penderita Dengan Kejadian Penyakit Jantung Koroner http://docplayer.info/45070157-Mahakamnursing-journal-vol-1-no-1-mei-2016-artikelpenelitian.html diakses tanggal 17 Oktober 2017
Sartono et.al.(2016). Basic Trauma Cardiac Life Support. Bekasi: GDMI

Sipolo, Berliany Venny (2011)..Upayapencegahan Serangan Berulang yang dilakukan Pasien Penyakit Jantung Koroner (PJK) http://arperpus.balikpapan.go.id/jurnal/web/pdf/K ESEHATAN-SAKIT-JANTUNG.pdf diakses tanggal 8 Juni 2018

Sumiati, Rustika, et.al. 2010. Penanganan Stress pada Jantung Koroner.. Jakarta. CV Trans Info Media.

www.WHO.int/mediacentre/factsheets/fs317/en/Cardiov ascular diseases diakses tanggal 18 Oktober 2017 